\title{
30. LABORATORY MEASUREMENTS OF COMPRESSIONAL WAVE VELOCITIES AND ELECTRICAL RESISTIVITY OF BASALTS FROM DSDP LEG 49
}

\author{
P.N. Chroston, C.J. Evans, and C. Lee, \\ School of Environmental Sciences, University of East Anglia, Norwich, U.K.
}

\section{INTRODUCTION}

Data are presented showing the variation of compressional wave velocity $(\mathrm{Vp})$ and electrical resistivity with increasing confining pressure for basalt samples from Holes $407,408,409$, and 412A. In addition, Vp has been measured on two samples with varying temperatures but constant confining pressure. Knowledge of the seismic properties of the basalts is important for interpretation of seismic refraction lines. Similarly, laboratory measurements of the electrical resistivity are valuable in understanding the conductivity structure of the crust.

The samples were subsequently to be used for thermal conductivity measurements, and a detailed study of their petrology was not made. The site descriptions and sample examination show that the samples from Hole 407 are generally fine- to medium-grained aphyric basalts with rare microphenocrysts of plagioclase in a groundmass of clinopyroxene and plagioclase. There is some alteration to smectitie in all the sections. The three samples from Hole 408 are aphyric sub-variolitic basalt, and are highly vesicular. Thin sections show plagioclase and olivine embedded in glass, with alteration of the glass and olivine to smectite. The one sample from Hole 409 is a highly vesicular aphyric basalt with some microphenocrysts of plagioclase and olivine. The sample from Hole $412 \mathrm{~A}$ is a medium-grained basalt with phenocrysts of plagioclase, olivine, and clinopyroxene. Phenocrysts are up to $2 \mathrm{~mm}$ in diameter, and occupy between 5 and 10 per cent of the rock.

\section{METHOD}

The samples were cylinders, $2.52 \mathrm{~cm}$ in diameter, 1.15 to $2.05 \mathrm{~cm}$ long after being cut and lapped to give smooth ends. Measurements of the compressional wave velocity employed a pulse-transmission method, and the electrical conductivity measurements used an AC bridge. The stainless steel transducer holders acted as electrodes, thus enabling both parameters to be measured on a sample under identical conditions of confining pressure, pore water pressure, and temperature. All samples were saturated in a seawater solution. The transducers and sample were enclosed in a jacket to prevent contamination of the pore fluid by the confining pressure medium (Plexol oil). A heater coil around the sample allowed temperature control. The pore water pressure was kept at zero for all measurements, apart from those where the temperature was varied. A summary of the results of the measurements is given in Table 1.

\section{COMPRESSIONAL-WAVE VELOCITIES}

Figure 1 shows the effect of increasing confining pressure on the compressional wave velocity. Measurements of veloc- ity were made both when the pressure was being increased and when it was decreased, but only those velocities obtained on the increasing part of the cycle are shown. Fairly close agreement was obtained between the two velocities, though in general the velocities on the decreasing part were slightly lower than on the increasing part. A similar effect has previously been observed by Christensen (1976) on basalts from Leg 35 . The velocities obtained are within the range of values previously obtained for DSDP basalts (Christensen and Salisbury, 1975; Salisbury and Christensen, 1976) and there is a clear relationship between velocity and density (Figure 2 ). The regression line for these few samples is given by

$$
\mathrm{Vp}=3.80 \phi-5.27 \mathrm{~km} / \mathrm{s}
$$

where $\Phi$ is density. The linear relation obtained by Christensen and Salisbury (1975) for a much more comprehensive suite of samples was

$$
\mathrm{Vp}=3.56 \phi-4.26 \mathrm{~km} / \mathrm{s}
$$

It has been observed (Christensen et al., 1975) that velocities increase with basement recovery depth. This relationship, however, is not evident for the six samples from Hole 407, which show a considerable scatter of values over a depth range of 114 meters.

The effect of temperature on $V p$ was studied on two samples. Only a limited temperature range was used, to reduce the risk of any thermal damage to the specimen. The confining pressure was fixed at $1.5 \mathrm{kbar}$ and the pore water pressure was fixed at $1.0 \mathrm{kbar}$. The results are shown in Figure 3 . The two samples showed differential velocity gradients of approximately -2.4 and $-3.4 \times 10-{ }^{4}{ }^{\circ} \mathrm{C}-{ }^{1}$, values somewhat higher than others previously obtained for mafic rock (e.g., Birch, 1958). However, it should be noted that because of the need to preserve the sample in good condition for thermal conductivity measurements, no rigorous study of the stability of the thermal effect was conducted. The recycling was fairly rapid; it has been established (Spencer and Nur, 1976, and work of present authors) that if the sample is left at its highest temperature for some hours, then the velocities on the decreasing part of the cycle may be higher, although the differential velocity gradient would be the same.

\section{ELECTRICAL RESISTIVITY}

The effect of increasing confining pressure on electrical resistivity is shown in Figure 4. In general, there is a marked increase in resistivity with increased pressure (up to about $0.25 \mathrm{kbar}$ ) and then a much slower increase of approximately 5 to 25 per cent (up to $1.5 \mathrm{kbar}$ ). The increase in resistivity can be explained if conduction is essentially via the fluid 
TABLE 1

Summary of Compressional Wave Velocities and Resistivities

\begin{tabular}{|c|c|c|c|c|c|c|c|c|c|c|c|}
\hline \multirow{3}{*}{$\begin{array}{c}\text { Sample } \\
\text { (Interval in } \mathrm{cm} \text { ) }\end{array}$} & \multirow{3}{*}{$\begin{array}{l}\text { Density } \\
\left(\mathrm{g} / \mathrm{cm}^{3}\right)\end{array}$} & \multicolumn{5}{|c|}{ Pressure in kbar } & \multicolumn{5}{|c|}{ Pressure in kbar } \\
\hline & & 0.00 & 0.25 & 0.50 & 1.00 & 1.50 & 0.00 & 0.25 & 0.50 & 1.00 & 1.50 \\
\hline & & \multicolumn{5}{|c|}{ Compressional Wave Velocity $(\mathrm{km} / \mathrm{s})$} & \multicolumn{5}{|c|}{ Resistivity (ohm-m) } \\
\hline $407-36-3,80-82$ & 2.86 & 5.68 & 5.77 & 5.81 & 5.84 & 5.84 & - & 93 & 97 & 99 & 101 \\
\hline $407-38-2,140-142$ & 2.82 & 5.25 & 5.40 & 5.41 & 5.44 & 5.45 & - & - & - & - & - \\
\hline 407-38-3, unknown & 2.91 & 5.75 & 5.75 & 5.76 & 5.76 & 5.77 & 12 & 116 & 81 & 51 & 47 \\
\hline $407-39-2,60-62$ & 2.83 & 5.30 & 5.39 & 5.38 & 5.43 & 5.44 & 16 & 81 & 82 & 83 & 83 \\
\hline $407-42-1,69-71$ & 2.90 & 5.53 & 5.86 & 5.83 & 5.83 & 5.84 & 76 & 102 & 103 & - & 104 \\
\hline $407-46-2,42-44$ & 2.67 & 3.89 & 4.40 & 4.51 & 4.60 & - & 7 & 22 & 24 & 25 & 26 \\
\hline $408-36-1,98-100$ & 2.63 & 4.75 & 4.84 & 4.84 & 4.87 & 4.89 & 11 & 58 & 59 & 60 & 61 \\
\hline $408-37-1,125-130$ & 2.59 & 4.12 & 4.32 & 4.35 & 4.39 & 4.43 & 8 & 21 & 20 & 19 & 19 \\
\hline $408-38-2,20-25$ & 2.44 & 4.15 & 4.25 & 4.27 & - & - & 5 & 15 & 15 & - & - \\
\hline $409-9-3,136-138$ & 2.77 & 5.03 & 5.30 & 5.29 & 5.29 & 5.29 & 8 & 48 & 50 & 53 & 59 \\
\hline $412 \mathrm{~A}-3-2,77-80$ & 2.98 & 5.51 & 5.93 & 6.01 & 6.03 & 6.04 & 15 & 95 & 105 & 115 & 126 \\
\hline
\end{tabular}

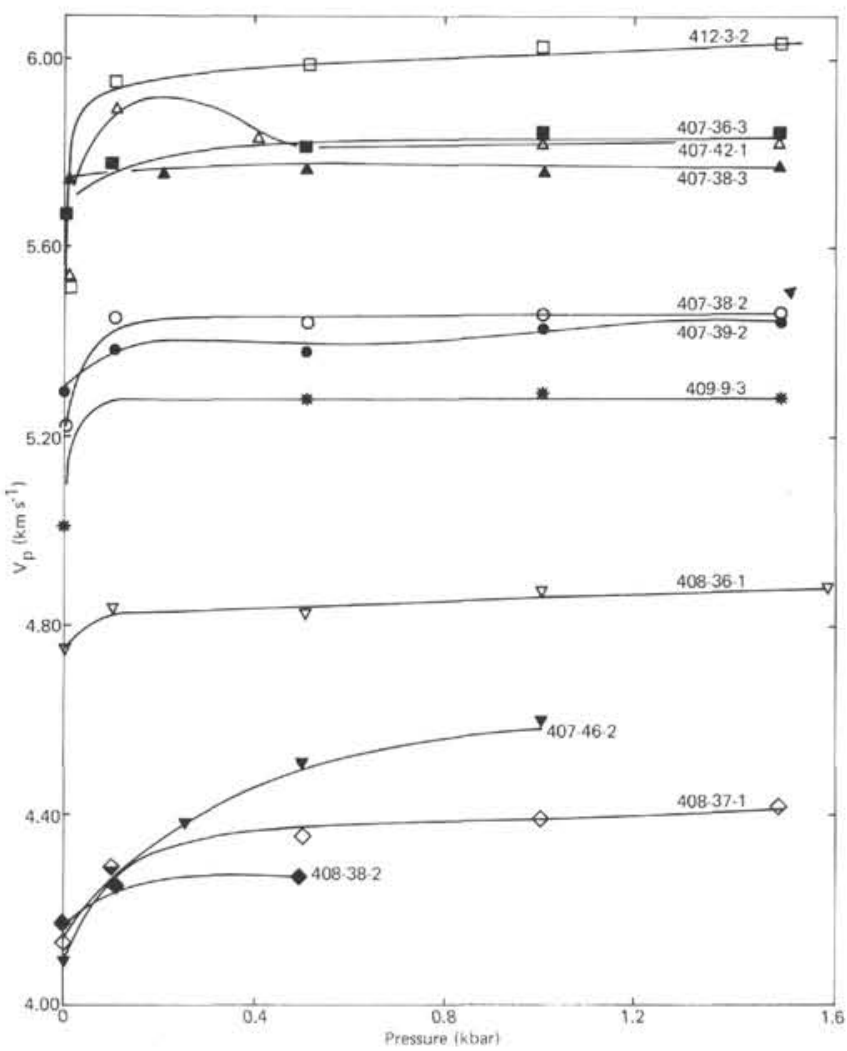

Figure 1. Variation of compressional wave velocity ( Vp) with increasing confining pressure.

content and the pores and cracks are becoming progressively closed (Brace et al., 1965; Brace and Orange, 1968). Two samples, however, showed some significant decrease in resistivity after an initial increase. This puzzling feature might be explained if the sample were only partially saturated; a similar effect has been observed by Brace and Orange (1968) on continental rocks, and by Hyndman and Ade-Hall (1974) for basalts from Leg 26 . The velocity changes for the same samples do not show any abnormal characteristic. Measurements of resistivity on a few samples on a decreasing pressure part of the cycle show slightly higher values than on upward

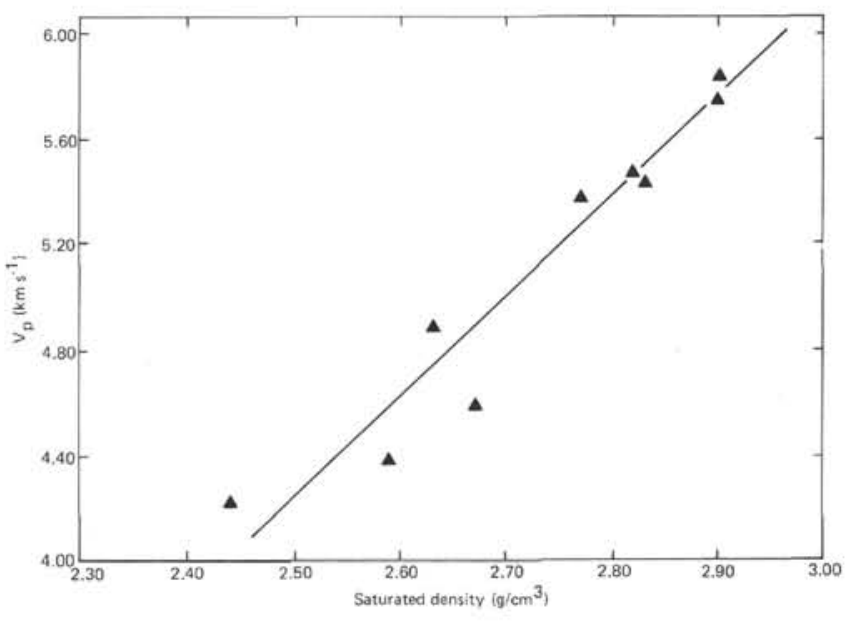

Figure 2. Compressional wave velocity (Vp) at 0.5-kbar pressure and densities.



Figure 3. Variation of compressional wave velocity (Vp) with temperature $(T)$. 


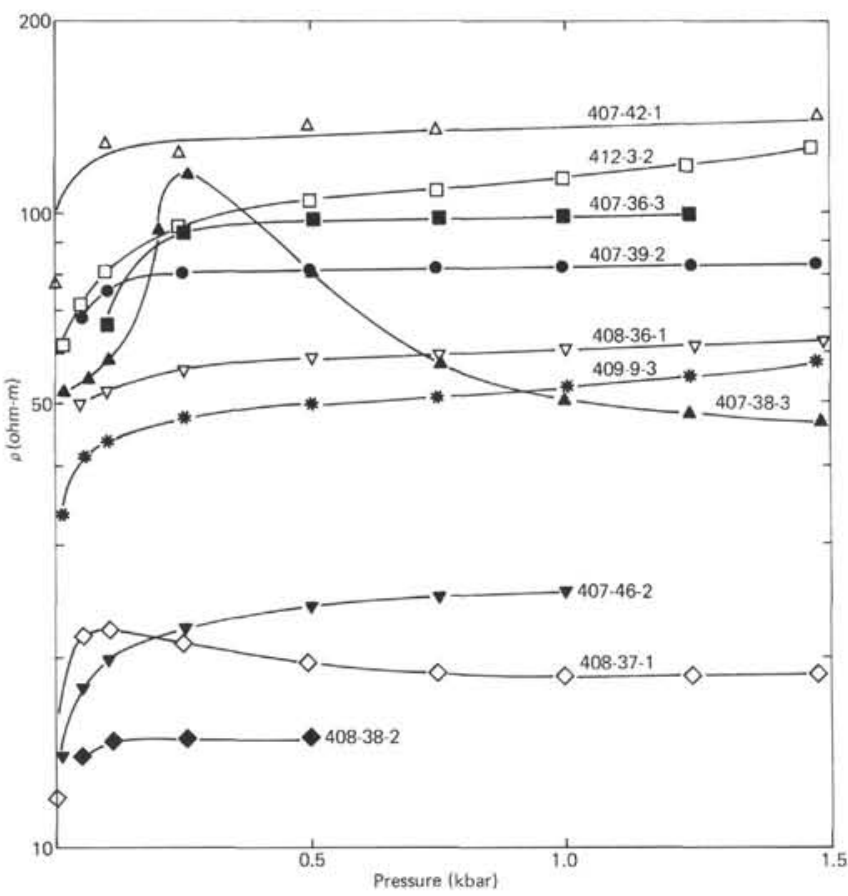

Figure 4. Variation of electrical resistivity $(\rho)$ with increasing confining pressure.

cycles, no doubt because of some pores and cracks failing to open or only partly opening after closure. The very low values of resistivity obtained (15 to $140 \mathrm{ohm}-\mathrm{m}$ ) are consistent with the range of values on DSDP basalts found by other workers (Hyndman and Ade-Hall, 1974; Hyndman and Drury, 1976).

\section{ACKNOWLEDGMENT}

We thank Professor J.R. Cann for reading the manuscript and for helpful comments.

\section{REFERENCES}

Birch, F., 1958. Interpretation of the seismic structure of the crust in the light of experimental studies of wave velocities in rocks. In Ingerson, E. (Ed.), Contrib. Geophys. Int. Ser. Monogr. Earth Sci., New York (Pergamon), p. 158.

Brace, W.F., and Orange, A.S., 1968. Further studies of the effect of pressure on the electrical conductivity of rocks, J. Geophys. Res., v. 73, p. 5407.

Brace, W.F., Orange, A.S., and Madden, T.R., 1965. The effect of pressure on the electrical resistivity of water saturated crystalline rocks, J. Geophys. Res., v. 70, p. 5669.

Christensen, N.I., 1976. Seismic velocities, densities, and elastic constants of basalts from DSDP Leg 35. In Hollister, C.D., Craddock, C., et al., Initial Reports of the Deep Sea Drilling Project, v. 35: Washington (U.S. Government Printing Office), p. 335.

Christensen, N.I. and Salisbury, M.H., 1975. Structure and constitution of the lower oceanic crust, Rev. Geophys. Space. Phys., v. 13, p. 57.

Christensen, N.I., Carlson, R.L., Salisbury, M.H., and Fountain, D.M., 1975. Elastic wave velocities in volcanic and plutonic rocks recovered on DSDP Leg 31. In Karig, D.E., Ingle, J.C., et al., Initial Reports of the Deep Sea Drilling Project, v. 31: Washington (U.S. Government Printing Office), p. 607.

Hyndman, R.D., and Ade-Hall, J.M., 1974. Electrical resistivity of basalts from DSDP Leg 26. In Davies, T.A., Luyendyk, B.P., et al., Initial Reports of the Deep Sea Drilling Project, v. 26: Washington (U.S. Government Printing Office), p. 505.

Hyndman, R.D. and Drury, M.J., 1976. The physical properties of oceanic basement rocks from deep drilling on the Mid-Atlantic Ridge, J. Geophys. Res., v. 81, p. 4042.

Salisbury, M.H. and Christensen, N.I., 1976. Seismic velocities of basalts from DSDP Leg 34, In Hart, S.R., Yeats, R.S., et al., Initial Reports of the Deep Sea Drilling Project, v. 34: Washington (U.S. Government Printing Office), p. 543.

Spencer, J.W. and Nur, A.M. 1976. The effects of pressure, temperature and pore water on velocities in Westerly Granite, $J$. Geophys, Res., v. 81, p. 899. 